\title{
Review of current and future approaches to the management of benign prostatic hyperplasia
}

\author{
J.C. Gingell
}

Department of Urology, Southmead Hospital, Westbury-on-Trym, Bristol BS10 5NB, UK

\section{Introduction}

Benign prostatic hyperplasia (BPH) is an agerelated disorder, found in a majority of men by the time the seventies are reached. Only a proportion of these will undergo surgical intervention, however; in the USA it has been estimated that the probability of a 40 year old man undergoing a prostatectomy during is lifetime is $29 \%$. $^{1}$ This suggests that there are large numbers of men with enlarged prostates and symptoms of bladder outflow obstruction who for one reason or another are at present untreated, and this is confirmed by population surveys. ${ }^{2-4}$ What do we know about the natural history of BPH and what if anything can be done to favourably modify it? What are the results of surgical treatment and what alternatives to surgery are available in the management of BPH? How can we identify and optimize the management of BPH in patients with different stages of the disease? These questions will be addressed in this article and future approaches to the management of BPH identified.

\section{Aetiology of BPH}

Prostatic hyperplasia is essentially a nodular condition arising in the periurethral glandular tissue. The process originates in the mid-prostatic urethra in the region of the entry of the ejaculatory ducts. ${ }^{5}$ Nodules enlarge and coalesce, causing inward compression of the prostatic urethra and outward displacement of the true prostatic tissue. The latter therefore becomes compressed as a narrow layer surrounding the enlarging hyperplastic tissue, separated from it by a mass of smooth muscle fibres.

Several cell types are concerned in the development of benign prostatic hyperplasia, including

Correspondence: J.C. Gingell, F.R.C.S.

Received: 2 March 1992 smooth muscle fibres, myoepithelial cells, fibroblasts and glandular epithelial cells. Within enlarging nodules the usual intercellular relationships are altered due to the varying rates of growth of the different cell types. ${ }^{6}$ Stereological studies have indicated that the increase in the volume of the stromal (smooth muscle and collagen) element is twice that of the glandular element.?

The aetiology of BPH is uncertain, but the prostate will develop, maintain normal size and function, and become hyperplastic only in men with normal androgen production. The principal prostatic androgen is dihydrotestosterone (DHT), an alpha-reduced metabolite of testosterone.

After the work of Siiteri and Wilson, ${ }^{8}$ it was thought for years that the prostates of men with BPH contained 3-4-fold higher tissue concentrations of DHT than normal glands, and this was considered fundamental to the pathogenic process. However this was later disputed by Walsh et al., and in fact BPH probably occurs in glands with normal levels of DHT or at least less elevated than previously thought. Recent research has focused on the possibilities of increased densities of androgen receptor populations and enhanced expressions of growth factors as pathogenic factors, with DHT playing essentially a permissive role.

Oestrogens are also thought possibly to have a role. Serum levels of 17 -oestradiol increase with age, and the net effect is to increase the oestradiol/ testosterone ratio. This may be relevant to the development of BPH as prostate stroma contains high levels of oestrogen receptors, and BPH is primarily a stromal disease. Further, 17-oestradiol has been shown to enhance the androgen receptor content of the prostate. ${ }^{10}$

In conclusion, we can say that BPH is a nodular condition affecting both stromal and glandular elements of the periurethral part of the prostate gland in the ageing male. Evidence strongly supports a key role for androgen-mediated factors in the pathogenesis of BPH, with a possible supporting role for oestrogens. 


\section{Natural history}

It is important to understand the natural history of BPH as this allows the clinician to anticipate what will happen if no treatment is given. In this context the study by Ball et al. ${ }^{11}$ is important. A review of 107 men with clinical BPH 5 years after initial presentation revealed that $9 \%$ underwent surgery, $32 \%$ had improvement in their symptoms and $16 \%$ worsening, while $43 \%$ were unchanged. Remarkably few patients who present in acute retention of urine have previously consulted their medical advisors regarding symptoms of bladder outflow obstruction or are on a waiting list for prostatic surgery.

\section{Symptoms of BPH}

Not all urinary symptoms in the ageing male are due to bladder outflow obstruction and bladder outflow obstruction may not be due to BPH. Patients' symptoms can fluctuate considerably and do not necessarily deteriorate with time. Outflow tract obstruction arises when the enlarging lobes of the prostate compress the urethra and impair bladder emptying. The response of the detrusor muscle to the obstruction varies and has a bearing on the urinary symptom complex as well as the pathological sequelae. The common symptoms attributed to bladder outflow obstruction due to BPH are hesitancy, a poor stream and terminal dribbling. The symptoms due to the response of the bladder to the outlet obstruction include frequency, urgency, nocturia and sometimes urge incontinence. Any or all of these symptoms may be present to a varying degree and of themselves are an unreliable index of the degree of obstruction or of prognosis in an individual case. Some of these symptoms, particularly frequency, urgency and nocturia, may occur in patients who do not have outflow obstruction and hence objective evidence must be obtained to make this diagnosis.

\section{Investigations}

Patients presenting with symptoms suggestive of bladder outflow obstruction should complete a frequency/volume chart over the course of a week. An estimate of the daily fluid intake is also useful information and may draw the patients' attention to a correctable cause of urinary frequency. A flow study is a necessary prerequisite to the diagnosis of outflow obstruction. This is undertaken by getting the patient to void into a flow meter which measures the volume of urine passed per unit time. Most flow meters give a graphic report and record of the flow pattern, indicating the degree of hesi- tancy, the peak flow rate and volume voided. Patients are instructed to void only when they have a desire to do so and immediately after voiding any residual urine can be accurately measured using transabdominal ultrasonography. At least two flow rates should be measured. Standard tests include a mid-stream specimen of urine for microbiology, blood urea, electrolytes and creatinine, the haemoglobin and prostate specific antigen (PSA). The latter test is a useful screening test for carcinoma of the prostate. A plain radiograph of the abdomen to include the kidneys, ureters and bladder (KUB) is usual to detect kidney, bladder or prostatic calculi. Prostatic size is not a reliable indicator of the severity of outflow obstruction and is only of importance to the urologist contemplating surgery or therapy designed to shrink the prostate. Digital rectal examination may detect obvious cancer of the prostate but is not accurate enough to exclude less advanced disease. If the PSA is elevated then transrectal ultrasound imaging of the prostate and guided biopsy is important in detecting early prostate cancer.

\section{Prostatectomy}

The operation of prostatectomy was initially performed to relieve retention of urine but, with the development of safer open surgery and the transurethral operation, the indications have widened to include men with symptomatic outflow obstruction. Except for the unusually large prostate requiring open enucleation, most prostates are best removed by transurethral resection (TUR). There are significant advantages to the patient having a TUR as opposed to open surgery. These advantages include minimal discomfort and a shorter hospital stay and convalescence. In most studies, mortality rates for TUR were lower than for open surgery, around $0.5-1 \%$ compared with $1.3-$ $2.5 \%$, attributed mainly to a lower incidence of pulmonary embolus and myocardial infarction. It is known that the longer the resection time the greater the incidence of perioperative and postoperative complications. ${ }^{12,13}$ This means that the larger the prostate or the less experienced the operator then the more complications are likely to be encountered. Mortality is known to be higher in non-specialist centres ${ }^{14,15}$ and approaching $20 \%$ of TURs will need reoperation after a 10 year followup period. ${ }^{16} \mathrm{~A}$ retrospective review from three different countries ${ }^{17}$ has confirmed the increased reoperation rate after TUR, but also surprisingly that there was a small but significantly increased risk of death, mainly from cardiovascular causes, when compared with the open operation, contradicting earlier data. The possible reasons for this remain obscure and are well reviewed in a leading

(


$\operatorname{article~}^{18}$ that pleads the case that there is "no room for complacency' by urologists.

\section{Non-surgical treatment of BPH}

There are two components contributing to bladder outflow obstruction by BPH: 'dynamic' and 'static'. The dynamic component is due to the smooth muscle component of BPH, its capsule and the bladder neck. The muscle cells are rich in alpha-receptors and respond to adrenergic stimulation by contraction and hence an increase in pressure within the prostatic urethra. Alphablockade therefore, by reducing muscular tone, should be beneficial in treating bladder outflow obstruction due to BPH. The static component of outflow obstruction due to BPH is due to the physical size of the fibroadenomatous enlargement of the prostate obstructing, distorting and compressing the urethra. As BPH is thought to be due to an alteration in the androgen/oestrogen ratio favouring oestrogen with advancing age, several therapeutic options become apparent to alter this state of affairs favourably.

\section{Treatment of the dynamic component: alpha adrenergic blockade}

Caine \& Perlberg ${ }^{19}$ first described alpha-blockade in the management of bladder outflow obstruction due to BPH. Phenoxybenzamine, however, blocked both $\alpha 1$ and $\alpha 2$ receptors and the incidence of side effects, mainly headaches, dizziness and postural hypotension, occurred in $30 \%$ of patients requiring cessation of treatment in $10 \%$. The presence of cerebrovascular disease or recent myocardial infarction were contraindications to treatment. Since that time more selective $\alpha 1$ blockers have been studied which exhibit fewer side effects. Prazosin,${ }^{20}$ terazosin, ${ }^{21}$ and indoramin ${ }^{22}$ have been shown to be beneficial in terms of improving the urinary flow rate and reducing urinary frequency. There are no long-term treatment results reported and the role of this group of drugs is at present to alleviate the symptoms of those patients waiting for surgery who do not experience side effects of the medication.

\section{Treatment of the static component: endocrine therapy}

From what is known regarding the aetiology of $\mathrm{BPH}$, the therapeutic potential of manipulating the hormone environment of the prostate gland and causing it to undergo involution or shrinkage is an exciting prospect that is currently being explored and is now a therapeutic reality. 5- $\alpha$-Reductase inhibitors which block the conversion of testo- sterone to the more active dihydrotestosterone are undergoing evaluation. The initial reports are encouraging. Finasteride (Proscar) competitively inhibits the enzyme 5- $\alpha$-reductase and induces a fall in intraprostatic dihydrotestosterone with no fall in plasma testosterone and hence no incidence of adverse antiandrogen or hypogonadal side effects. In a worldwide multicentre placebo-controlled study after one years' medication, the prostate volume as measured by transrectal ultrasound and magnetic resonance imaging was reduced in a significant number of patients. The symptoms of bladder outflow obstruction improved and there was a modest improvement in the measured urinary flow rate.$^{23}$ This study is now 'open ended' in that those patients who wished to continue on medication with finasteride have been allowed to do so and are now in the third year of study. One waits with interest to see whether there is a greater shrinkage of the prostate and improvement in symptoms with the further passage of time. The importance of a shift in the ratio of the androgen/ oestrogen ratio favouring oestrogen with advancing age has led to the investigation of aromatase inhibitors. Oestrogen receptors can be found in the stroma of BPH tissue and stromal stimulation can be induced by aromatizable substances such as androstenedione. These effects can be counteracted by aromatase inhibitors. Atamestane (Schering AG) is a new specific, steroidal aromatase inhibitor which selectively blocks oestrogen biosynthesis via the inhibition of the aromatization of androstenedione and testosterone. Oestrogen therapy deprivation might therefore represent a new useful treatment for BPH and phase II clinical trials have been commenced.

\section{New 'minimally invasive' techniques}

\section{Balloon dilatation}

Although dilatation of the bladder neck and prostate is an old concept, ${ }^{24,25}$ the recent interest in transurethral balloon dilatation of the prostate has developed from the success of transluminal angioplasty. ${ }^{26,27}$ The specially designed balloon is accurately inserted into the prostatic urethra either under direct vision or ultrasound control. Local urethral anaesthesia can be utilized in the unfit patient. The balloon is distended until rupture of the anterior commissure or prostate capsule occurs although this is not essential to achieve success in terms of an improved flow rate. ${ }^{28}$ No long-term results are available.

\section{Intra-prostatic stents}

An increasing range of stents for insertion into the 
prostatic urethra under local anaesthesia are now undergoing evaluation. These stents may be plastic coils for temporary use in the very poor risk patient or meshed metal tubes or coils for the longer term. Encrustation and displacement are not infrequent problems ${ }^{29}$ but an expanding stainless steel coil (urolume $^{\mathrm{TM}}$ ) has already been shown to be of value in urethral strictures ${ }^{30-32}$ as it becomes embedded and eventually covered by the urothelium. Preliminary results of the same stent used in patients with $\mathrm{BPH}$ and unfit for surgery have recently been reported. ${ }^{33-35}$ A gold-plated spiral (ProstaKath) is under evaluation and a rigid titanium stent (developed by ASI) inserted over a balloon into the prostatic urethra which is then expanded. All of these stents hold open the prostatic urethra by separating the lateral lobes of the prostate, are easy to insert and the newer designs minimize the risk of encrustation.

\section{Microwave}

Since the first reports of local microwave heat therapy ${ }^{36,37}$ applied by special probes either per rectum or perurethrally to the prostate this treatment has received a lot of publicity in the national press. Unfortunately at present there is little in the way of objective evidence to support the claims of the manufacturers of the rival devices. The technology is being further refined and developed so that increased heat is applied to the prostate with protection by simulatenous cooling of the urethral mucosa and immediate periurethral tissue.

\section{Discussion}

At the present time the majority of men seeking advice regarding the treatment of symptoms due to bladder outflow obstruction do so at a relatively advanced stage. Up to $40 \%$ of prostatectomies undertaken in the UK are for patients who have developed acute or chronic retention of urine. Some patients may have developed significant complications of prostatic obstruction with upper tract dilatation, obstructive uropathy and bladder decompensation. Transurethral resection of the prostate is the best treatment option if the patient is fit enough. If not an endoprostatic coil might be shown to be a better option than the alternative of an indwelling urethral catheter with its attendent restrictions and complications.

Transurethral prostatectomy can also be offered to patients with significant symptoms due to outflow obstruction. It provides a rapid and effective cure of troublesome symptoms which are often interfering with the patients work or limiting his social activities. Many such patients may be symptomatically improved by adrenergic blockade over the relatively short term. This group of drugs, although they may serve to defer it, are unlikely to replace surgery. Further information on microwave treatment of the prostate is awaited to determine whether this will have a significant role to play in this symptomatic group of patients.

The other major interest at the present time is whether medication can safely and effectively shrink the prostate without producing side effects, and hence relieve the patients' symptoms and prevent the subsequent need for prostatic surgery. These are sound theoretical grounds for thinking that this goal can be achieved with the advent of 5 - $\alpha$-reductase inhibitors. Uterine fibroids undergo involution and can disappear after the menopause due to the sudden change in hormone environment. Surgical castration, oestrogen therapy and, more recently, luteinizing hormone releasing hormone analogues and cyproterone acetate $e^{38}$ all reduce prostatic volume and improve the urinary flow rate. The universal side effects, however, of impotence and loss of libido and, depending on the medication, hot flushes and gynaecomastia, preclude the use of these agents in the treatment of BPH. It would seem, however, from the studies already undertaken that the administration of finasteride is not accompanied by significant side effects, and may yet be shown to arrest the development of BPH or indeed cause involution of the early established condition. Any such medication will of necessity have to be over the long term and preferably studied in patients with less advanced symptoms than currently seen at present by urologists. That there are many such patients available for study is apparent from a recent survey. ${ }^{4}$ The prevalence rate of BPH was 253 per 1,000 new screened (aged 40-79 years), rising from 138 per 1,000 men in the $40-49$ year age group to 430 per 1,000 in men aged $60-69$. This study has confirmed the suspicion among urologists that symptomatic $\mathrm{BPH}$ is far more common in the community than is apparent from the numbers presenting to general practitioners or urologists. Screening programmes in general practice are actively encouraged by the Department of Health and the opportunity therefore exists for patients with early BPH to be detected and offered treatment. The benefits of hormone replacement therapy for postmenopausal women are now well recognized and perhaps hormone manipulation of the middle-aged man will help to alleviate the workload of the urologist endeavouring to cope with the demands of providing prostatectomy for the ever increasing ageing male population.

\section{Acknowledgement}

I am grateful to $\mathrm{Mr} \mathrm{J}$. Cottrell, MSc for reading the manuscript and for his helpful advice and encouragement. 


\section{References}

1. Glynn, R.J., Campion, E.W., Bouchard, G.R. \& Silbert, J.E The development of benign prostatic hyperplasia among volunteers in the normative ageing study. Am $J$ Epidemol 1985, 121: 78-82.

2. Steyn, M. Just old age? A study of prostatism in general practice. Family Practice 1988, 5: 193-195.

3. Britton, J.P., Dowell, A.C. \& Whelan, P. Prevalence of urinary symptoms in men aged over 60 . Br J Urol 1990, 66: $175-176$.

4. Garraway, W.M., Collins, G.N. \& Lee, R.J. High prevalence of benign prostatic hypertrophy in the community. Lancet 1991, 338: 469-471.

5. McNeal, J.E. Origin and evolution of benign prostatic enlargement. Invest Urol 1978, 15: 340-345.

6. Wilson, J.D. The pathogenesis of benign prostatic hyperplasia. Am J Med 1980, 68, 745-756.

7. Rohr, H.P. \& Bartsch, L.G. Human benign prostatic hyperplasia: a stromal disease? Urology 1980, 16: 625-633.

8. Siiteri, P.K. \& Wilson, J.D. Didydrotestosterone in prostatic hypertrophy. 1 . The formation and content of dihydrotestosterone in the hypertrophic prostate of man. J Clin Invest 1970, 49: 1737-1745.

9. Walsh, P.C., Hutchins, A.M. \& Ewing, L.L. Tissue content of dihydrotestosterone in human benign prostatic hypertrophy is not supra-normal. J Clin Invest 1983, 72: 1772-1777.

10. Moore, R.J., Gazak, J.M. \& Wilson, J.D. Regulation of cytoplasmic dihydrotestosterone binding in dog prostate by 17 beta oestradiol. J Clin Invest 1979, 63: 351-357.

11. Ball, A.J., Feneley, R.C.L. \& Abrams, P.H. The natural history of untreated prostatism. Br J Urol 1981, 53: 613-616.

12. Chilton, C.P., Morgan, R.J., England, H.R., Paris, A.M..I. \& Blandy, J.P. A clinical evalution of the results of transurethral resection of the prostate. Br J Urol 1978, 50: 542-546.

13. Singh, M., Tressidder, G.C. \& Blandy, J.P. The evaluation of transurethral resection for benign enlargement of the prostate. Br J Urol 1973, 45: 93-102.

14. Ashley, J.S.A., Howlett, A. \& Morris, J.N. Case-fatality of hyperplasia of the prostate in two teaching and three Regional Board Hospitals. Lancet 1971, ii: 1308-1311.

15. Wennberg, J.E., Roos, N.P., Sola, L., Shoni, A. \& Jaffe, R. Use of claims data systems to evaluate health care outcomes: mortality and reoperation following prostatectomy. JAMA 1987, 257: 933-936.

16. Roos, N.P. \& Ramsey, E.W. A population based study of prostatectomy: outcomes associated with differing surgical approaches. J Urol 1987, 137: 1184-1188.

17. Roos, N.P., Wennberg, J.E., Malenka, D.J. et al. Mortality and reoperation after open and transurethral resection of the prostate for benign prostatic hyperplasia. N Engl J Med 1989 , 320: $1120-1124$.

18. Anon. TU or not TU. Lancet 1989, i: 1361-1362.

19. Caine, M., Perlberg, S. \& Shapiro, A. Phenoxybenzamine for benign prostatic obstruction. Urology 1981, XVII: 542-546.

20. Kirby, R.S., Coppinger, S.W.C., Corcoran, M.V., Chapple, C.R., Flannigan, M. \& Milroy, E.J.G. Prazosin in the treatment of prostate obstruction. Br J Urol 1987, 60: $136-142$.

21. Dunzendorfer, U. Clinical experience symptomatic management of BPH with terazosin. Urology 1988, 32 (Suppl): $27-31$.
22. Iacovou, J.W. \& Dunn, M. Indoramin - an effective new drug in the management of bladder outflow obstruction. Br J Urol 1987, 60: 528 .

23. Stoner, E. Phase III studies evaluating 5-alpha reductase inhibitor proscar. Special report to American Urological Association, 86th Annual Meeting, Toronto, 1991.

24. Mercier, F. Recherches sur les valvules du col de la vessie. In Hinman, F. (ed) Benign Prostatic Hypertrophy. SpringerVerlag, New York, 1983, pp. 30-340.

25. Deisting, W. Transurethral dilatation of the prostate: a new method in the treatment of prostatic hypertrophy. Urol Intervent 1956, 2: 158-171.

26. Castenada, F., Reddy, P.K., Wasserman, N. et al. Benign prostatic hypertrophy: retrograde transurethral dilatation of the prostatic urethra in humans. Radiology 1987, 163: $649-653$.

27. Reddy, P.K., Wasserman, N., Castaneda, F. \& CastanedaZuniga, W.R. Balloon dilatation of the prostate for treatment of benign hyperplasia. Urol Clin North Am 1988, 15: 529536.

28. Gill, K.P., Machan, L.S., Allison, D.J. et al. Bladder outflow tract obstruction and urinary retention from benign prostatic hypertrophy treated by balloon dilatation. Br J Urol 1989, 64: 618-622.

29. Nielsen, K.K., Klarskov, P., Nordling, J., Andersen, J.T. \& Holm, H.H. The intraprostatic spiral. New treatment for urinary retention. $\mathrm{Br} J$ Urol 1990, 65: 500-503.

30. Milroy, E.J.G., Chapple, C.R., El Din, A. \& Wallsten, H. A new treatment for urethral strictures: a premanently implanted urethral stent. J Urol 1989, 141: 1120-1122.

31. Sarramon, J.P., Joffre, F., Rischmann, P., Rousseau, H. \& Eb Din, A. Use of the wallstent endourethral prosthesis in theO treatment of recurrent urethral strictures. Eur Urol 1990, 18. 281-285.

32. Ashken, M.H., Coulange, C., Milroy, E.J.G. \& Sarramon J.P. European experience with the urethral wallstent fot urethral strictures. Eur Urol 1991, 19: 181-185.

33. Chapple, C.R., Milroy, E.J.G. \& Rickards, D. Permanently implanted urethral stent for prostatic obstruction in the unfit patient: preliminary report. $\mathrm{Br} J$ Urol 1990, 66: 58-65.

34. McLoughlin, J., Jager, R., Abel, P.D., El Din, A., Adam, A. \& Williams, G. The use of prostatic stents in patients with urinary retention who are unfit for surgery: an interim report. Br J Urol 1990, 66: 66-70.

35. Milroy, E.J.G. Permanent prostate stents. J Endourol 1991, 5: 75-78.

36. Lidner, A., Golomb, J., Siegel, Y. et al. Local hyperthermia of the prostate gland for the treatment of benign prostatic hypertrophy and urinary retention. $\mathrm{Br} J$ Urol 1987,60 : 567-571.

37. Servadio, C., Lidner, A., Lev, A., Leib, Z., Siegel, Y. \& Braf, $Z$. Further observations on the effect of local hyperthermia on benign enlargement of the prostate. World J Urol 1989, 6: 204-208.

38. Bosch, R.J.L.H., Griffiths, D.J., Blom, J.H.M. \& Schröder, F.H. Treatment of benign prostatic hyperplasia by androgen deprivation: effects on prostate size and urodynamic parameters. J Urol 1989, 141: 68-72. 